\title{
Study for Maritime Practice Control System for China Coast Guard
}

\author{
Yufeng Yang ${ }^{1,}$, , Mingkui Feng ${ }^{2, b}$ \\ ${ }^{1}$ Department of Ship Conducting, China Maritime Police Academy, Ningbo, 315801, China \\ 2 Department of Ship Conducting, China Maritime Police Academy, Ningbo, 315801, China \\ aemail: yyf41212@163.com, bemail:fmkjg@sohu.com
}

Keywords: China Coast Guard; AIS; Beidou; Maritime Training; Management and Control Systems

\begin{abstract}
Maritime practice is based on the professional educational objectives and teaching programs, an important teaching developed according to theory with practical principles that is an important way to improve the Coast Guard navigational skills. The primary data is collected from AIS and Beidou system, which is developed maritime practice control system for China Coast Guard. After marine police trainees practiced at sea, their ship track will be playback on an electronic chart, then, each module integrated maritime practice, final assessment will has been given for them.
\end{abstract}

\section{Introduction}

Maritime practice at sea has become an important practical compulsory course of maritime police academy for the trainees. This process is not only the students understanding and experiencing the process of ship life, but also the process of learning navigation knowledge and technology. To improve the students to carry out a major maritime emergency support service expertise and marine police force to deal with the growing number of major maritime service mission. As marine police vessels experimental teaching demonstration center the basis for highly qualified teaching staff for the development of the experimental team, this paper built and developed ship practice management and control systems based AIS in order to help students effectively identify ships, to help track suspects target, information exchange, inter-ship collision avoidance, improved maritime communications function, in the enforcement process to grasp the target ship in the waters under the jurisdiction and dynamic suspected ship.

\section{Control System Design Ideas}

Currently, foreign AIS technology has matured, and there are many mature product shipment. Most of the domestic ship has also been equipped with AIS equipment. Due to confidentiality reasons, study abroad military AIS was little publicly about the results [1]. While domestic military AIS had been still in the research stage, some products and equipment has been equipped to the ships. Research on Military AIS system, we can learn about the art of civil AIS, combined with the needs of military navigation and maritime police on duty law enforcement, the equipment with military characteristics can be developed.

In paper, using $\mathrm{B} / \mathrm{S}$ technology, browser and server, ship GPRS and AIS are parsed and stored and displayed on the online platform of electronic chart. Students can log in the system through a browser, navigate a practice ship real-time traffic conditions of the waters. The system can also provide inquiry that this practice ship could be searched from the dynamic placement of thousands of ships. Meanwhile, the system will provide query capabilities of the ship sailed historical trajectory data, students can check the ship's position of the past at some point, practice state and the ship's trajectory over a certain period of time, or even the occurrence of a maritime accident replay process.

Serial communication hardware and the peripheral circuits are built in GPS-BD2 module, interfaces with the computer hardware research. The data acquisition and analysis system is designed. According to the raw data collected, a single point positioning accuracy of the practice 
ship is analyzed, to improve the positioning accuracy by Kalman filter algorithm. Beidou system is used for effective monitoring when the ship far offshore. Coast Guard vessels at sea is to carry out practice teaching and assessment on practice management and control system after network completed.

\section{Several Key Technologies of the Control Systems Development}

AIS information is digitized or compression encoding in order to take full advantage of the communication channel that received by ship AIS equipment, which also need to be decoded in accordance with the format to get the real information they contain [3]. To compensate for AIS data blockage causes the update data is not timely, resulting in inaccurate or ship trajectory error larger problem, Kalman filter algorithm is used to make appropriate modifications [4], [5], [6]. The system noise and measurement noise is introduced, system state is done by the least squares method on the ships AIS data observation to estimates the ship trajectory smoothing and prediction that ship trajectory can be more accurately estimated. Figure 1 and Figure 2 respectively are AIS data sources of the maritime police and ship information decoded.

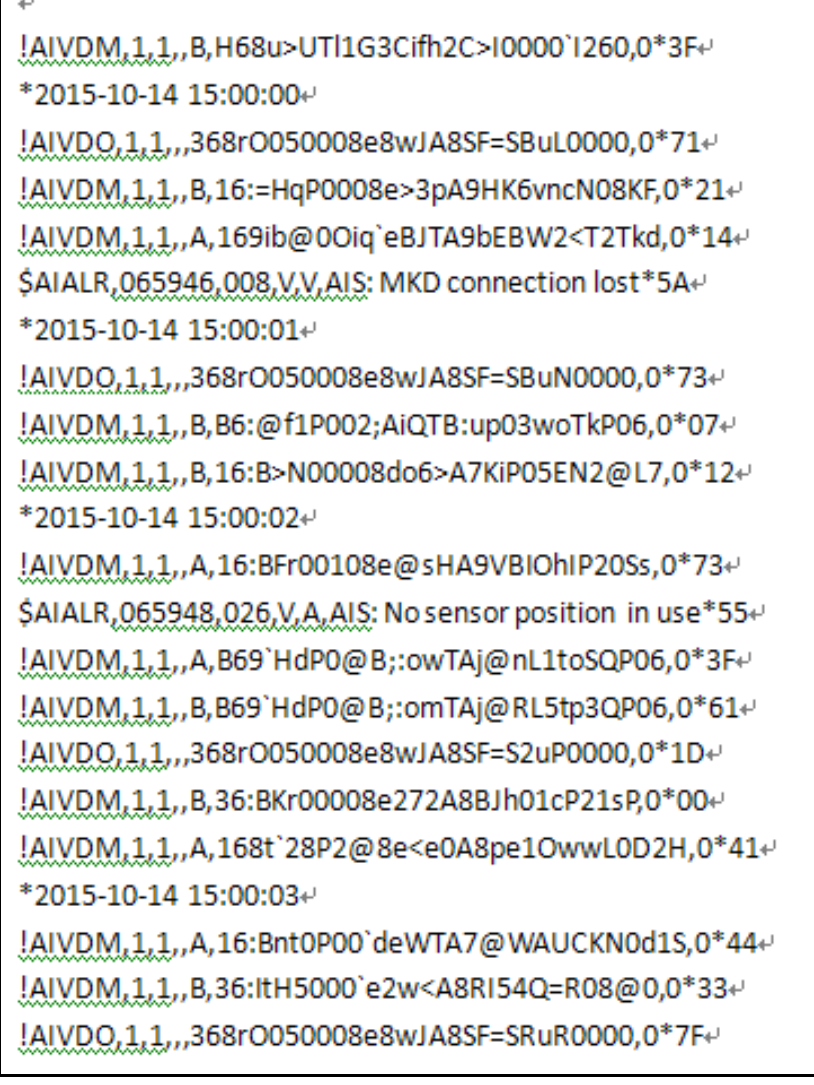

Fig.1. AIS data sources of the maritime police

\begin{tabular}{|llll|}
\hline HAI JING & & & \\
\hline FLAG STATE: & CHINA & LOG: & $121042.55 \mathrm{E}$ \\
MMSI: & 412000000 & LAT: & $29056.59 \mathrm{~N}$ \\
CALLSIGN: & 25 TX & MILEAGE: \\
IMO: & 10101 & DESTINATION: QINGDAO \\
TYPE: & OTHER & ETA: & $15 / 10 \quad 12: 00$ \\
LENGTH: & $35 \mathrm{M}$ & SPEED: & $0.5 \mathrm{KN}$ \\
BREADTH: & $5 \mathrm{M}$ & COURSE: & 086 \\
DRAFT: & $3 \mathrm{M}$ & TIME: & $2015-10-14 \quad 11: 53: 13$ \\
\hline
\end{tabular}

Fig.2. Ship information decoded

GPS-BD2 module is constructed based SOC chip by correlator, FFT and matched filter hybrid applications and optimization algorithms. The hardware peripheral circuits is built by the mature electronic components on the basis of that, serial communication interface with the computer hardware, $\mathrm{PC}$ program is wrote based $\mathrm{VC}$ and $\mathrm{VB}$, thus completing the data acquisition and analysis system design and acquisition of Beidou and GPS the original signal. 


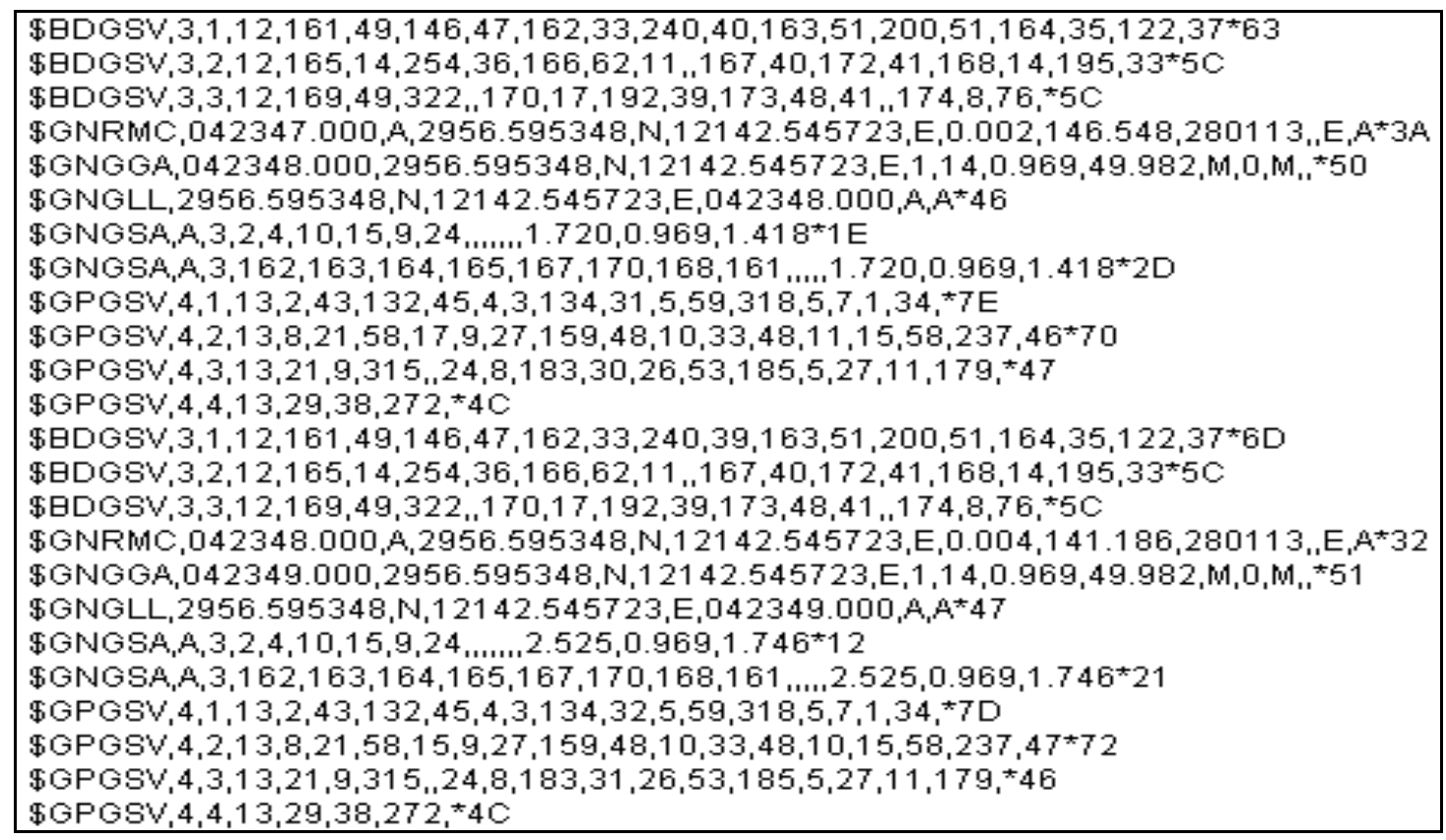

Fig.3. Beidou and GPS data

Experimental data collected from Beidou development board is as shown in Figure 3. The data in each row can display up to four satellites. BDGSV is analyzed here. The first number in each row is the number of messages received, the second number is the received message number, the third number is the number used satellite positioning, the fourth number is the number of the first satellite, The fifth number is satellite elevation, the sixth number is the azimuth of the satellite, the seventh number is the satellite carrier noise ratio, the data behind* representation the checksum. Such as the first line of data:

\$ BDGSV, 3,1,12,161,49,146,47,162,33,240,40,163,51,200,51,164,35,122,37* 63

In the type(1): it is found based on the BDGSV that 3 is the number of messages received, 1 represents the first message, 12 is received a total of 12 satellites, 161 is the number of the first satellite, 49 is satellite elevation, 146 is satellites azimuth, 47 is satellite carrier noise ratio, the next four data is the case of the second satellite, then third satellite, the fourth satellite. Beidou location information parsed see Figure 4 and the satellite state see Figure 5.

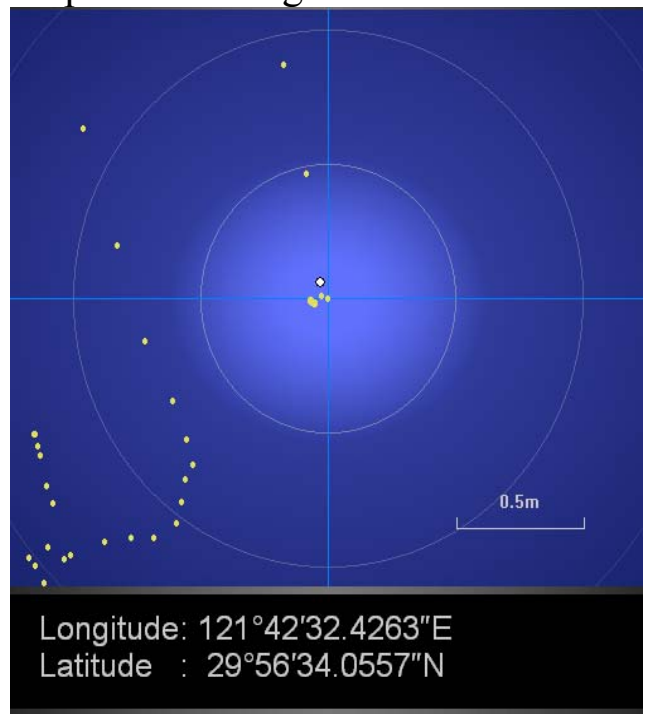

Fig.4. Beidou location information parsed

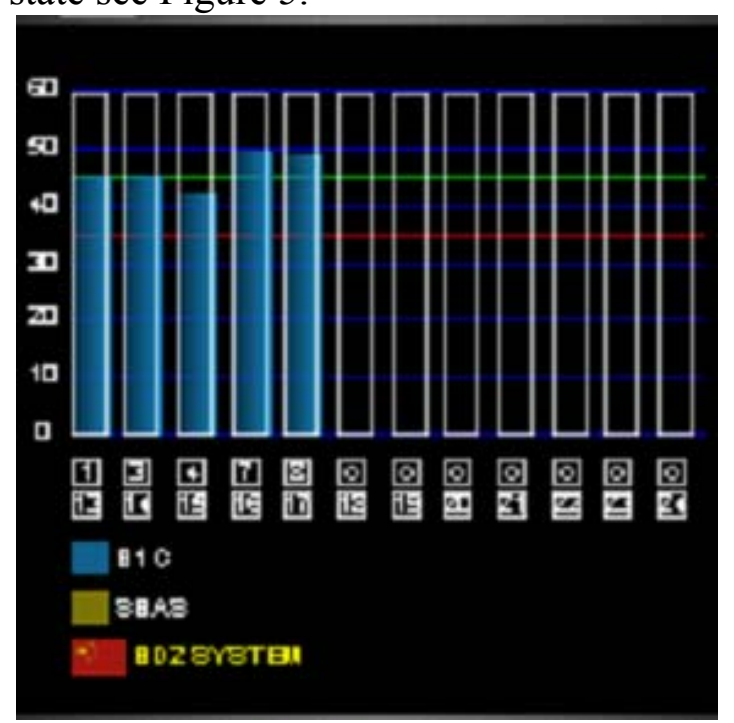

Fig.5. Beidou satellite status information

Ship dynamic information server is connected through TCP / IP protocol, ship dynamic information is received and analyzed, and the ship dynamic information stored in the database. Ship dynamic information received will be constructed index by dynamic information database in order to improve student access. Electronic chart database is for saving Chinese coastal obtained by preprocessing different scale electronic chart picture and its index. Web server application server 
receives the request forwarded participants, select from the ship dynamic information database and student information database of student data needed, forwarded to the student browser by a Web server, conducted by processing and display by javascript program. The practice management and control platform see Figure 6 and Figure 7.

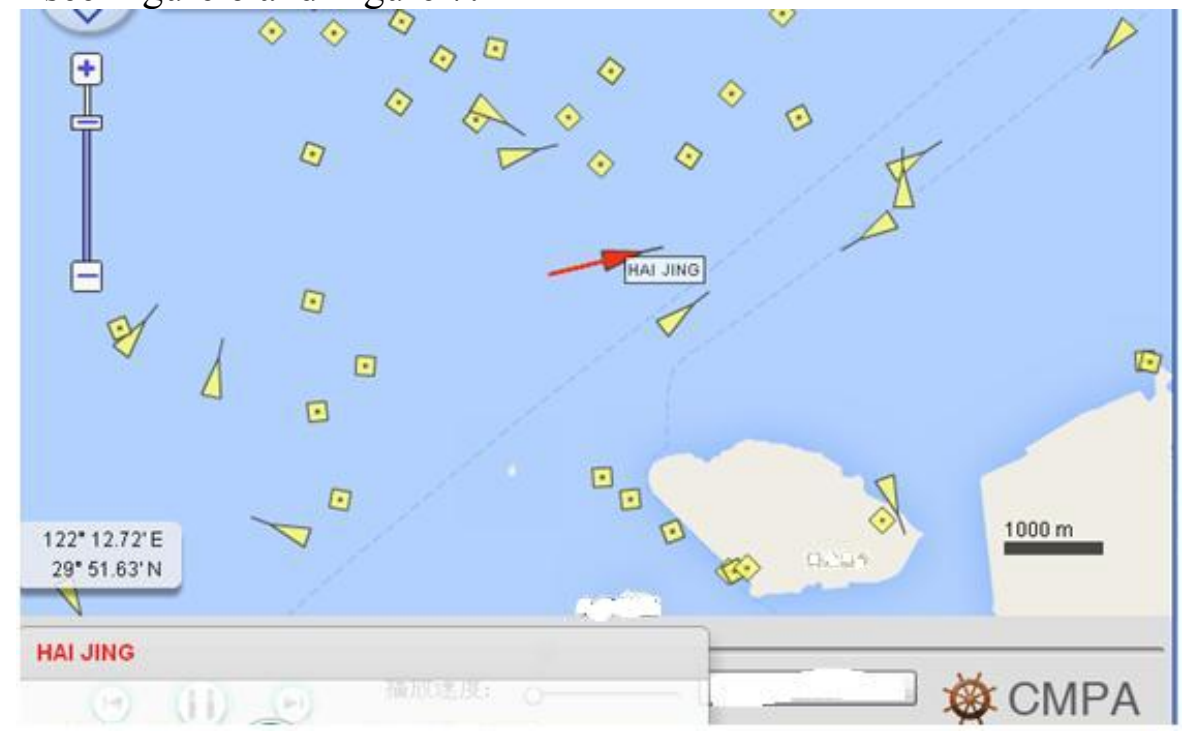

Fig.6. Practice management and control platform

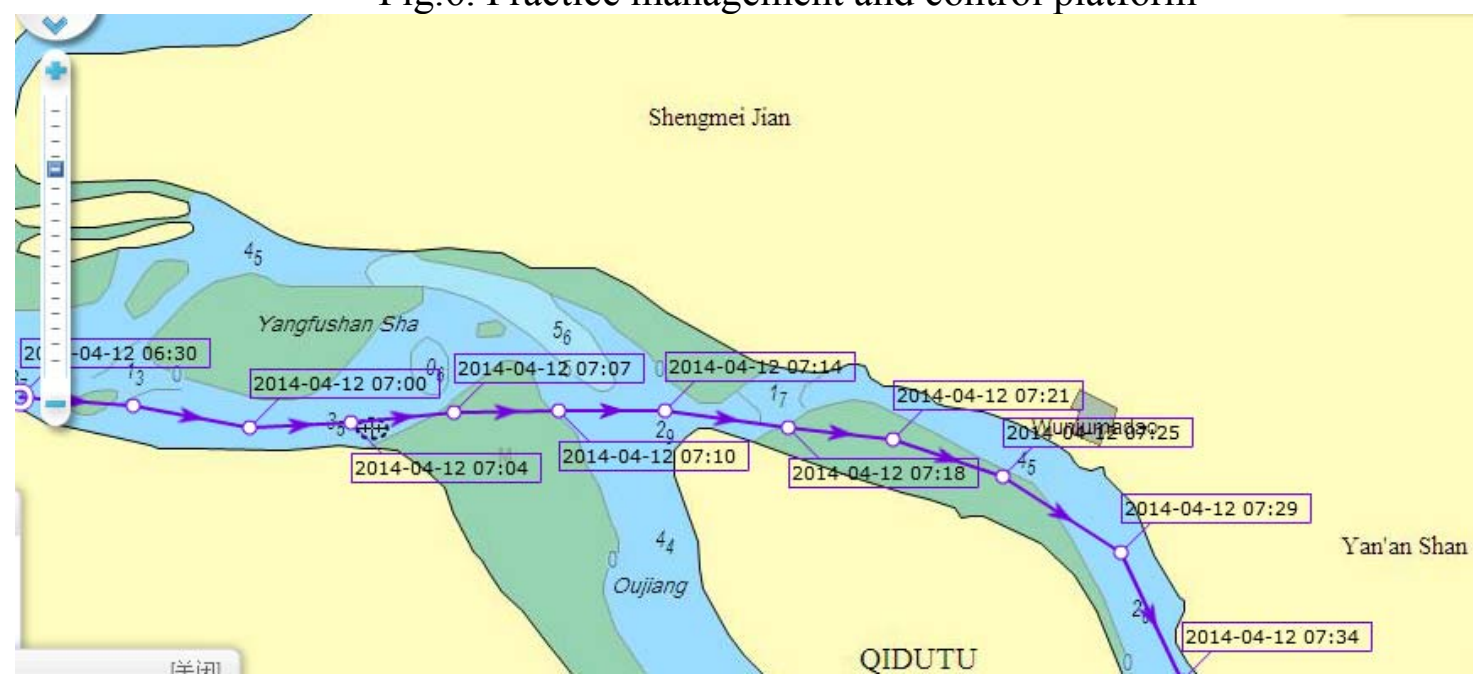

Fig.7. Practice management and control platform

\section{Conclusion}

The ship integrated practice control systems is developed based on AIS and Beidou in order to support the law enforcement duty for marine police force, provide tactical support of precise positioning and navigation for the ships, to provide technical support for the monitoring of ships and target ship. As a basis, it is built a real traction, combat training in one, comprehensive experimental platform, Havens worked hard, scouring at the sea type of intensive training mode, in order to resolve marine police vessels multidisciplinary comprehensive training and assessment problems. In this platform, innovative ability of the students will be improved and maritime police instructors achieved academic research capacity upgrade in the new techniques, tactics, maritime rights hot and difficult issues research.

\section{Acknowledgement}

In this paper, the research was sponsored by University Laboratory Research Project in Zhejiang (Project No. YB201428), Zhejiang Annual Research in 2015, National Education Science Planning Education Key Topics (Project No. DIA150308), Higher Education Reform Project in Zhejiang 
Province in 2015 (Project No.JG2015207) and China Maritime Police Academy Research Development Fund Project.

\section{References}

[1] Wei Chi, Aiguo Shi. Military ship Automatic Identification System[J]. Ship Science and Technology, 2003, 1(25).

[2] Lijun Wang, Sisi Wang. Internship Training Program based Offshore Ship Handling Simulator[J]. Maritime Education Research.2010,1.

[3] Zhenguo Ding. Computer AIS information analysis realization study[J]. China Water Transport. 2008,8(10).

[4] Tie Xu, Fengjun Cai, Qinyou Hu. Estimation of Ship AIS Track Based on the Kalman Filter Algorithm [J]. Modern Electronic Technology. 2014, 37(5).

[5] Qinyou $\mathrm{Hu}$ et al. Bring Live AIS Information on the WebSea Charts by Using Ajax, Proceedings of ITST 2008, Sophia Antipolis, France, June 6-8,2007, p455-459.

[6] IEC61993-2: Maritime navigation and radio communication equipment and Systems-Automatic identification systems (AIS)-Part2: Class A shipborne equipment of the universal automatic identification system (AIS)-operational and performance requirements, methods of test and required test result. 